How to Cite

Ezenwa, O., Stella, A., \& Agu, A. O. (2018). Effect of competitive intelligence on competitive advantage in Innoson technical and industry limited, Enugu state, Nigeria. International Journal of Business, Economics \& Management, 1(1), 26-37.

https://doi.org/10.31295/ijbem.v1n1.25

\title{
Effect of Competitive Intelligence on Competitive Advantage in Innoson Technical and Industry Limited, Enugu State, Nigeria
}

\author{
Obiefuna Ezenwa \\ University of Nigeria Enugu, Nsukka, Nigeria \\ Corresponding author email: adaobiezenwa@yahoo.com \\ Adaobi Stella \\ University of Nigeria Enugu, Nsukka, Nigeria \\ Agu Okoro Agu \\ Evangel University Akaeze Ebonyi State, Akaeze, Nigeria
}

\begin{abstract}
The study sought to determine the effect of strategic intelligence on technological know-how in a manufacturing firm, ascertain how innovation promotes brand reputation in the manufacturing firm and examine the extent of the relationship between human intelligence and employee loyalty in the manufacturing firm. The study had a population size of 1258, and of which a sample size of 303 was realized using Taro Yamane's formula at $5 \%$ error tolerance and $95 \%$ level of confidence. The instrument used for data collection was primarily questionnaire and interview. Out of 303 copies of the questionnaire that were distributed 283 copies were returned while 20 were not returned. The survey research design was adopted for the study. The hypotheses were tested using Pearson product moment correlation coefficient, chi-square, and simple linear regression statistical tools. The findings indicated that strategic intelligence significantly affects technological know-how in Nigeria manufacturing firm $(r=0.602 ; F=3$. 426E3; $1=4.426 ; p$ <0.05). Innovation significantly relationship affects brand reputation in the Nigeria manufacturing firms (X2 $0=68.270$ is greater than the Chi-square table value X2 $1=9.49 ; p<0.05$ ). There is a significant relationship between human intelligence network and employee loyalty in the manufacturing firm $(r=$ 705, $P<05)$. The study concluded that competitive intelligence is a vital tool for strategic planning and competitive advantage. The study recommended that there should be an adequate investment in competitive intelligence process, facilities, and activities by manufacturing firm so as to be innovating in their product, services and competitive dispositions. In implementing competitive intelligence in an organization, employees should be equipped with the knowledge, skill and technical know-how of handling intelligence product.

Keywords---competitive advantage, competitive intelligence, employee loyalty, human intelligence, innovation and brand reputation.
\end{abstract}

\section{Introduction}

The business world is dynamic and unpredictable (Raynor, 2007). To adapt and survive in this kind of business environment, enterprises must implement competitive intelligence (CI) (Adidam et al., 2012) competitive intelligence is the most powerful business tool of the $21^{\text {st }}$ century that will aid decision-makers in an ever-increasing competitive market and it can be utilized for the offensive and defensive purpose. Competitive intelligence (CI) plays a significant role in business management and practice. Management of companies has relied on competitive intelligence information to support decisions to give them an edge over their competitors. Companies use intelligence information to stay abreast and be in tune with the business environment (Cynthia et al., 2014).

In order to achieve this objective company must be aware of competitors sharing the same supplier and about their relative position from a supplier's perspective (Bromwich, 1990; Chen, 1996). However, most companies

ISSN 2632-9476

Received Jan 10, 2018 / Accepted Jun 20, 2018 / Published Jul 05, 2018 
neglect to consider competitor intelligence in purchasing decisions (Bergen \& Peteraf, 2002: Schiele, 2012). This results in a company's inability to determine whether and how competitive advantage was gained in purchasing activities (Ramsay, 2001).

Competitive intelligence is a process of controlling the competitive environment with the aim of providing useful information from competitors (Bose, 2008). Competitive intelligence is a necessary concept in the management process and strategic planning of the company. Companies that use competitive intelligence in analyzing competitor's strengths and weaknesses are able to predict opportunities for market development and have better performance rather than competitors (Britt, 2006).

Competitive intelligence is business tools that help organizations in the process of strategic management and increase business performance through enhancing knowledge, internal communications, and strategic plans quality. Competitive intelligence gives an organization competitive advantage through forecasting and developing their markets. Also by analyzing the behavior of the competitors and identifying opportunities within the business environment which in the long run will lead to innovation (Rezaie et al., 2011).

The competitive intelligence is a formal program of gathering information on a company's competitors. It is one of the fastest growing fields of strategic management (Wheelen \& Hunger, 2010). Competitive intelligence is the practice of examining the external competitive environment, direct rivals, economic regulatory matters, and more, to support the development of more resilient, robust strategy and tactics.

The intelligence outcome is meaningful, actionable, and provides insights about change and future developments and their implications to the organization. Competitive intelligence improves tactical and strategic decision-making through understanding the competitive environment. No business is an island. To succeed, the business will need to deal with customers, suppliers, employees, and other organizations offering similar products (Viviers, 2005).

Competitive intelligence is a very important tool for an organizational strategic planning and management process. The formal exploration process and management of the marketing strategic paradigm has been linked with the environmental scanning interactive as a basis for gathering and processing the information and the information processing theory paradigm, (Dishman \& Calof, 2008).

\section{Statement of the Problem}

A typical Nigerian organization in the private sector generally lacks the culture of information gathering critical to developing competitive intelligence architecture that confers competitive advantage. This assertion is based on the near absence of functional research and development units in most of these organizations as observed in their website.

The major problem of the Nigeria manufacturing sector is the failure to acknowledge the fact that the business environment has become very competitive, dynamic and only those organizational with the right information capabilities can succeed in the modern times. Because of this problem, many organizations did not take the issue of intelligence seriously and therefore failed to create a competitive intelligence department. In most of the organizations where it exists, it was discovered that it is either not functional or not fully engaged in the activities of information gathering, analysis, and dissemination of intelligence needed for effective competitiveness which is a serious challenge in the manufacturing industry. Consequently, because of the lack inadequate generation of intelligence, most of the organizations do not have an in-depth knowledge about existing products, customers, competitors, stakeholders and other environmental relationships that are required to enable managers and business executives make quality strategic decision, again, this has led to the culture of poor innovation, customer dissatisfaction, poor quality of products and high cost of production of goods and services. This experience has further weakened the ability of the manufacturing organizations to compete favorably in order to attain high performance. There is also the general problem of inadequate knowledge of competitor's orientation, customer orientation, and the cognate process of organizational learning capability and how this can improve the quality of competitive intelligence that will lead to increase organization performance. Therefore, the study focuses on the effect of competitive intelligence on competitive advantage in a manufacturing firm.

\section{Objectives of the Study}

The specific objectives of this study include the following:

1. To determine the effect of strategic intelligence on technological know-how in a manufacturing firm.

2. To ascertain how innovation promotes brand reputation in the manufacturing firm.

3. To examine the extent of the relationship between human intelligence networks and employee loyalty in the manufacturing firm. 


\section{Research Questions}

To achieve the above objectives, the following research questions were raised:

1. What is the effect of strategic intelligence on technological know-how in a manufacturing firm?

2. How does innovation affect brand reputation in the manufacturing firm?

3. What is the extent of the relationship between human intelligence networks and employee loyalty in the manufacturing firm?

\section{Research of Hypotheses}

The study proposes the following hypotheses

1. Strategic intelligence significantly affects technological know-how in a manufacturing firm.

2 Innovation significantly affects brand reputation in the manufacturing firm.

3. There is a significant relationship between human intelligence networks and employee loyalty in the manufacturing firm.

\section{Review of Related Literature}

\section{Conceptual framework: Competitive Intelligence}

McGonagle \&Vella (1999) see competitive intelligence as the use of public sources to locate and develop data that are then transformed into information, generally about competitive, competitors and the market environment in the broadest sense. Wheelen \& Hunger (2010) cited in Ezigbo \& Uduji (2013) define competitive intelligence as a formal program of gathering information on company's competitors. It is one of the fasted growing fields within strategic management.

According to Hoffman (2006), Competitive Intelligence is a structured judicious method and informing strategy and an innovation engine that draws better business outcomes. SCIP (2007) cited in Krugaer (2010) defines competitive intelligence as a systematic and can affect a company's plans, decisions, and operations. It shows that competitive intelligence is information oriented and the information must be useful to organizational plans, decisions, and operations.

Competitive intelligence is seen as actionable recommendations arising for a systematic process that involves planning, gathering, analyzing and dissemination of information on the external environment for opportunities or developments that have the potential to affect a company's or country's competitive situation (Calof \& Skinner, 1993 cited in Nasri (2012). Competitive intelligence is a continuous process of gathering data, information and the knowledge about actors (Competitors, customers, suppliers, government etc) which interact with the organization in the business environment in order to enrich the decision making the process for enhancing the competitiveness of organization (Poppa, 2002 cited in Nasri (2012).

\section{Sources of Competitive Intelligence}

A common way to classify the sources of $\mathrm{CI}$ is to divide them into primary and secondary data sources (Bergeron \& Hiller, 2002). Primary data sources consist of direct observations, participation on trade shows or seminars, reverse engineering and human intelligence networks. Human intelligence networks by itself is a wide area as it can contain several types of contents, for example, employees, clients, competitors, consultants, journalists, government officials, shareholders, and suppliers. Secondary data sources are resources that already exist and are not directly related to the specific problem at hand (Nair, 2009).

Secondary data sources are, for example, online databases and other internet sources, journals and company's internal documents (Bergeron \& Hiller, 2002). Also, social media falls into the category of secondary data sources (Bergeron \& Hiller, 2002).

Considering the secondary data sources, it is always important to consider the quality of the data accurate it is (Nair, 2009). A researcher should also consider the suitability and adequacy of the data which depends on the project at hand (Nair, 2009). 
Benefits of Competitive Intelligence

Malrz \& Kohli (1996) state that many organizations failed to use market information that is freely available to them. This issue has resulted in greater emphasis on competitive intelligence due to competing organizations having access to the same intelligence to the foundation of good intelligence is to provide the necessary intelligence to the decision maker in time to make a difference and in time to take the correct action.

The true difference among organizations is no longer based on the information they acquire, but rather on how they interpret, disburse and exploit the information, (Buhler, 2003). The ability to use correctly this information is the source of an organizations' competitive advantage (Malrz \& Kohli, 1996).

Competitive Intelligence is increasingly being considered as an important, mandatory component of each organization's overall strategy and functioning, this is because, competitive intelligence has the ability to boost an organization's bottom line if used and developed in the correct way, based on the organization's needs, internal organization and competitive (McGongle \& Vella, 2004). Competitive Intelligence has earned its rightful position as an acknowledged business discipline and has become a major technique for achieving competitive advantage and organization performance (Saayman \& Muller, 2005).

Competitive Intelligence's purpose is thus to gain strategic advantage and includes competitor intelligence, as well as intelligence gathered on customers, suppliers, technologies, environments, and business relationships, which gives the ability to predict movements in the competitive environments, reducing the uncertainty of managerial decisions (Saayman \& Muller, 2005).

The ultimate goal of competitive intelligence is to provide actionable intelligence which consists of information that has been synthesized, analyzed, evaluated and conceptualized. To achieve this goal, organizations need to create a corporate culture of promoting a culture of competitiveness, allowing for the exchange of knowledge and ideas among individuals and departments (Viviers et al., 2005).

\section{Competitive Advantage}

A competitive advantage can be attained if the current strategy is value-creating and not currently being implemented by present or possible future competitors (Barney \& Hesterly, 2006). Although a competitive advantage has the ability to become sustained, this is not necessarily the case. A competitive firm can enter the market with the resource that has the ability to invalidate the prior firm's competitive advantage, which results in reduced rents (Barney, 1995). Sustainability in the context of a sustainable competitive advantage is independent with regards to the time-frame. Rather, a competitive advantage is sustainable when the efforts by competitors to render the competitive advantage redundant have ceased (Rumelt, 2984). When the imitative actions have come to an end without disrupting the firm's competitive advantage, the firm's strategy can be called sustainable. This is contrary to other views (e.g. Porter) that a competitive advantage is sustainable when it provides above-average returns in the long run (Porter, 1985).

\section{The Strategic Intelligence and Technological Know-how}

The strategic intelligence includes collecting, and analyzing the environmental data and distributing this information on the strategy of the organizations (Kuosa, 2011). The strategic intelligence includes rules, functional affairs and tax, political and economic extent, and human resources categories of the organizations. In order words, the strategic intelligence considers and analyzes the social, political and economic behavior of the organizations. The strategic intelligence is evaluated with the factors such as the strategies vision, human and social resources, and the economic and political issues of the organizations (Gabber, 2007).

\section{Human Resources Intelligence and Employee Loyalty}

The role of the human factor in progressing community affairs is very important and is considered as the most effective factor in the social, cultural, and economic changes. The social and economic developments require a particular attention to the human resources and its intelligence (Coyne \& Bell, 2011). In a managerial environment; conceptually, the intelligent human resources are defined as entities that are able to perceive a certain status and act according to some instructions and approached. Human resources intelligence implies to the analysis power of information concerning the decision-making areas of human resources such as the rewards and benefits, personnel relations, selections, recruitments, and the statues of the workforce in the competitive environment (Booker et al., 2008). 
In fact, the Technological intelligence assesses the present and new technologies as well as predicting the future technologies and dealing with basic researchers, patents, etc. Technological intelligence is evaluated by the factors like the fundamental and applied research level, the number of articles, and having safe industrial processes (Gabber, 2007). Also, Technological intelligence is a new tool for the strategic intelligence through which it presents a mechanism to create stable systems of the knowledge management towards the present technologies. Technological intelligence evaluates the benefits and expenses of the new and present technology and the future discontinuity technology (Viviers et al., 2005). Generally, this intelligence includes information gathering from articles, papers, fundamental and applied researchers, methods, norms, and industrial processes (April \& Bessa, 2006).

\section{Theoretical Framework}

\section{Competitive Forces Theory of Organization}

One of the competitive forces theories of the organization is the five forces analysis developed by Porter (2008) as a framework to analyze the level of competition within an industry and business strategy development. The theory which was drawn upon the industrial organization and economics derived five forces that determine the competitive intensity and therefore attractiveness of a market. The theory described attractiveness to mean that the overall profitability and argued that unattractive industry is one in which the combination of these five forces act to drive down overall profit. The theory emphasized that a very unattractive industry approaches pure competition in which available profits for all organizations are driven to normal profit.

\section{Empirical Review}

Ezigbo \& Uduji (2013) in their empirical study titled managing competitive intelligence for strategic advantage. The study discovered that competitive intelligence is necessary because managers need it to increase the quality of product and services, strategic planning and market knowledge, competitive intelligence is used by gathering information, converting it into intelligence and utilizing it in business decision making. The cost for competitive intelligence consists of time, money and intellectual skills, the study also revealed that there is a significant relationship between competitive intelligence and strategic advantage.

Nwokah \& Ondukwu (2009) carried out a study on competitive intelligence and marketing effectiveness in corporate organizations in Nigeria. The study reported that there a strong association between competitive intelligence and marketing effectiveness of corporate organizations in Nigeria. It was also observed in the study that competitive intelligence leads to marketing effectiveness in corporate organizations in Nigeria. The research concluded that the study significantly refines the body of knowledge concerning the impact of competitive intelligence and marketing effectiveness of the corporate organization in Nigeria. The study recommended that management should consistently motivate its intelligence team so that it could analyze customer's needs and seek to satisfy them.

Nemtanhela \& Iyamu (2001) carried out a study on the impact of competitive intelligence on products and services innovation in organizations, the study was conducted on information and communication technology (ICT) organizations in Pretoria, South Africa. The study revealed that competitive intelligence in overemphasized as revolutionary customer-focused information systems products while services remain challenging, it was also discovered that not all organizations that deploy competitive intelligence produce more innovative method. The study observed that lack of knowledge sharing and limitations within the organizational culture were found to be important factors for the deployment of competitive intelligence products and services in the organizations. The study concluded that the role of competitive intelligence in product and service innovation is to inform strategic management reflect customer needs and inform rivals about the competitors and help the organization to locate themselves on the competitive scale.

Rizwan et al., (2014) conducted a study on competitive intelligence and Marketing Effectiveness of Organizations; An Investigation from Pakistan. The specific objective is too, determine the effect of market opportunities on market efficiency, to ascertain how competitive threat is used in an organization to make their effective, to examine how competitor risk are used in an organization to make their market effective, to determine how technical intelligence is used in an organization to make their effective. The study adopted survey research design. Findings indicated that market opportunities are significantly used in organizations to make their marketing 
effectiveness. Competitor threats are significantly used in organizations to make their marketing effectiveness. Competitor risks are significantly used in organizations to make their marketing effectiveness. Technical intelligence is significantly used in organizations to make their marketing effectiveness. The study concluded that Competitive intelligence is a tool through which business can gain competitive advantage and compete against their competition. The study recommended that organizations should adopt strategic competitive intelligence that will place them ahead of their competitors.

Ngugi et al., (2011) examined intelligence practices and their effects on profitability of commercial banks in the Kenyan banking industry. The study discovered that all the variables examined in the study have positive significant effects on the profitability of commercial banks in Kenya. It was emphasized in the study that technological intelligence is the most significant factor in contributing to the profitability of the commercial banks in Kenya. The study concluded that technology, product, market and strategy alliance competitive intelligence practices affect the profitability of commercial banks in Kenyan.

Mahmoud (2014) concluded a study on the effect of the strategic intelligence on the strategic decision making and strategic planning in organization and companies using the intelligence system in the Khorram-Abad city. According to the results, this study is an analytical-survey research. The statistical population for the research is the companies and organizations using intelligence systems in Khorran-Abad which were estimated using Cochran formula the random sampling-stratification method with a sample size of 150 . The research tool is a questionnaire which was confirmed through content validity method and its stability by Cronbach's Alpha. In this research, both the structural equation approach and the AMOS 18 software have been used to study and test the hypothesis. The result shows that the strategic intelligence has a positive and meaningful effect on the strategic decision making and strategic planning in the companies and organizations using intelligent systems in Khorran-Abad. In addition, the effective factors on the strategic intelligent, human resource intelligence, organization process, technological information, financial resources, competitor, and customer intelligence were recognized.

Fatemeh \& Habib (2014) investigated the Relationship Between Technology Intelligence and Business Performance. In this study, the effect of technology intelligence on four aspects of the business performance was examined. Technology (Competitive) intelligence pursues the following objectives: becoming timely aware of the technological events, identifying new products and processes, and understanding trends and events relevant to the competitive environment. The statistical population for this research study was employees from companies of the industrial city of Ardabil. This study was based on the data collected from a sample of the managers and engineers in the late 2012 and early 2013. The data required for evaluation was gathered through questionnaires and analyzed by SPSS. The results showed a significant relationship between technology intelligence and four aspects of business performance. The study concluded for companies to survive, they need to be knowledge oriented and have specialists at their disposal for directing and supervising the performance of organizations which can be achieved through systematic feedback from coworkers, customers, and managers. They recommended that companies should use this method meticulously, as this can make their strategist more optimistic about making firmer decisions, and moving ahead alongside the changing environment.

\section{Research Method}

The study adopted survey method by administering structured questionnaire with the aim to gather primary data from the staff of Innoson Technical limited Emene with regard to competitive intelligence and competitive advantage. The scope of the study covered the staff of Innoson Technical limited. The population of the study is 1258. A sample size of 303 was determined using Taro Yamane and the validity of the instrument was given to management experts who modify and made the necessary correction so that the instrument can measure what it ought to measure. The reliability was obtained using Cronbach's Alpha, which had a value of 0.670 , which indicates that there is the internal consistency of the instrument. Out of the 303 questionnaires, 283 were correctly filled and returned. The hypotheses were tested using Pearson Product moment correlation coefficient, Chi-square, and Simple linear regression. 


\section{Results and Analysis}

Table 1

Strategic Intelligence on technological know-how in the manufacturing firm

\begin{tabular}{lllll}
\hline Questionnaire items & $\begin{array}{l}\text { Agree/strongly } \\
\text { agree }\end{array}$ & $\begin{array}{l}\text { Disagree/strongly } \\
\text { disagree }\end{array}$ & Undecided & Total \\
\hline $\begin{array}{l}\text { Launching of a new product can } \\
\text { derive from a technological know-how }\end{array}$ & 209 & 54 & 20 & 283 \\
$\begin{array}{l}\text { Technological know-how ensure that } \\
\text { managers think ahead of their }\end{array}$ & 233 & 40 & 10 & 283 \\
$\begin{array}{l}\text { competitor in the launching of a new } \\
\text { product }\end{array}$ & 442 & & & \\
Total & 94 & 30 & 566 \\
\hline
\end{tabular}

Source: Fieldwork, 2015

According to the table (1) based on aggregate response 442 (78\%) indicated strongly agree, 94(17\%) indicated disagree while $30(5 \%)$ indicated undecided. This implies that strategic intelligence significantly affects technological know-how in the manufacturing firm.

Table 2

Model Summary ${ }^{b}$

\begin{tabular}{llllllll}
\hline Model & $\mathrm{R}$ & $\mathrm{R}$ Square & $\begin{array}{l}\text { Adjusted R } \\
\text { Square }\end{array}$ & $\begin{array}{l}\text { Std. The error of } \\
\text { the Estimated }\end{array}$ & $\mathrm{F}$ & $\mathrm{t}$ & $\begin{array}{l}\text { Durbin- } \\
\text { Watson }\end{array}$ \\
\hline 1 & $.602^{\mathrm{a}}$ & .559 & .668 & .53372 & $3.426 \mathrm{E} 3$ & 4.825 & .050 \\
\hline
\end{tabular}

a. Predictors: (Constant), strategic intelligence

$\mathrm{R} \quad=0.602$

$\mathrm{R}^{2} \quad=0.559$

$\mathrm{F} \quad=3.426 \mathrm{E} 3$

$\mathrm{T} \quad=4.426$

$\mathrm{DW} \quad=0.050$

\section{Interpretation:}

The regression sum of squares (975.890) is greater than the residual sum of squares (147.555), which indicates that more of the variation in the dependent variable is not explained by the model. The significance value of the $\mathrm{F}$ statistics (0.000) is less than 0.05 , which means that the variation explained by the model is not due to chance.

$\mathrm{R}$, the correlation coefficient which has a value of 0.602 , indicates that there is a positive relationship between strategic intelligence and technological know-how. R Square, the coefficient of determination, shows that $85.9 \%$ of the variation in technological know-how is explained by the model.

With the linear regression model, the error of estimate is low, with a value of about .53372. The Durbin Watson statistics of 0.050 , which is not more than 2 , indicates there is no autocorrelation.

The strategic intelligence coefficient of 0.602 indicates a positive significant relationship between strategic intelligence and technological know-how, which is statistically significant (with $\mathrm{t}=4.426$ ). Therefore, the null hypothesis should be rejected and the alternative hypothesis accordingly accepted. 
Table 3

Innovation significantly affects brand reputation in the manufacturing firms

\begin{tabular}{lllll}
\hline Questionnaire items & $\begin{array}{l}\text { Agree/strongly } \\
\text { agree }\end{array}$ & $\begin{array}{l}\text { Disagree/strongly } \\
\text { disagree }\end{array}$ & Undecided & Total \\
\hline $\begin{array}{l}\text { Innovation ensure that brand } \\
\text { reputation is maintained }\end{array}$ & 242 & 36 & 5 & 283 \\
$\begin{array}{l}\text { Good brand reputation increase } \\
\text { organizational sale through innovation }\end{array}$ & 263 & 15 & 5 & 283 \\
Total & 505 & 51 & 10 & 566 \\
\hline
\end{tabular}

Source: Fieldwork, 2015

According to the table (3) based on aggregate respond $505(87 \%)$ indicated strongly agree, 51(9\%) indicated disagree while $10(2 \%)$ indicated undecided. This implies that innovation significantly affects brand reputation in the manufacturing firm.

Table 4

Chi-Square Tests Computed from the Frequency Cross Tabulation

\begin{tabular}{llll}
\hline & Value & Df & Asymp. Sig. (2-sided) \\
\hline Pearson (Chi-square & 68.270 (a) & 4 & .006 \\
Likelihood Ratio & & & .004 \\
Linear-by-linear & 18.911 & 4 & .507 \\
Association & .441 & 1 & \\
N of Valid Cases & 566 & 1 & \\
\hline
\end{tabular}

Table 4 is the output of the computed Chi-Square values from the cross tabulation statistics of observed and expected frequencies with the response options of agree and disagree based on the responses of the research subjects. Pearson Chi-Square computed value $\left(X^{2}{ }_{c}=68.270\right)$ is greater than the Chi-Square tabulated value $\left(X^{2}{ }_{t}=9.49\right)$ with 4 degrees of freedom (df) at 0.05 level of alpha $\mathrm{X}_{\mathrm{c}}^{2}=68.270, \mathrm{p}<.05$ )

\section{Decision Rule}

The decision rule is to accept the alternative hypothesis if the computed Chi-Square value is greater than tabulated Chi-Square value otherwise accept the null hypothesis.

\section{Decision}

Since the Pearson Chi-Square computed $\mathrm{X}_{\mathrm{c}}{ }_{\mathrm{c}}=68.270$ is greater than a Chi-Square table of value $\mathrm{X}_{\mathrm{t}}{ }_{\mathrm{t}}=9.49$, the null hypothesis is rejected and alternate hypothesis is accepted. Thus, we concluded that innovation significantly affects brand reputation in the manufacturing firm.

Table 5

Human Intelligence Networks and Employee Loyalty in the Manufacturing Firm

\begin{tabular}{lllll}
\hline Questionnaire items & $\begin{array}{l}\text { Agree/strongly } \\
\text { agree }\end{array}$ & $\begin{array}{l}\text { Disagree/strongly } \\
\text { disagree }\end{array}$ & Undecided & Total \\
\hline $\begin{array}{l}\text { Seeing employee as internal customer } \\
\text { promote employee loyalty }\end{array}$ & 273 & 7 & 3 & 283 \\
$\begin{array}{l}\text { Employee loyalty can be achieved } \\
\text { when employees realized that their }\end{array}$ & 260 & 21 & 2 & 283 \\
$\begin{array}{l}\text { interest in build inside the organization } \\
\text { goal }\end{array}$ & 533 & 28 & 5 & 566 \\
Total & & & & \\
\hline
\end{tabular}

Source: Fieldwork, 2015 
According to the table (5) based on aggregate response 533(94\%) indicated strongly agree, 28(5\%) indicated disagree while $5(1 \%)$ indicated undecided. This implies that there is a significant relationship between human intelligence networks and employee loyalty in the manufacturing firm.

Table 6

Descriptive Statistics on Human Intelligence Networks and Employee Loyalty in the Manufacturing Firm

\begin{tabular}{lccc}
\hline & Mean & Std. Deviation & $\mathrm{N}$ \\
\hline Human intelligence network & 1.8261 & 1.16043 & 283 \\
Human intelligence network & 1.8261 & 1.6043 & 283 \\
Employee loyalty & 1.9065 & 1.26713 & 283 \\
\hline
\end{tabular}

Table 7

Correlations Statistics on Human Intelligence Networks and Employee Loyalty in the Manufacturing Firm

\begin{tabular}{llll}
\hline & & $\begin{array}{l}\text { Human intelligence } \\
\text { network }\end{array}$ & Employee loyalty \\
\hline $\begin{array}{l}\text { Human intelligence } \\
\text { network }\end{array}$ & Pearson Correlation Sig. (2 tailed) & 1 & $.705^{* *}$ \\
& $\mathrm{~N}$ & 283 & .000 \\
Employee loyalty & Pearson Correlation Sig. (2 tailed) & $705^{* *}$ & .000 \\
& $\mathrm{~N}$ & & 283 \\
& $\mathrm{~N}$ & 283 & 1 \\
& & 283 \\
\hline
\end{tabular}

** Correlation is significant at the 0.01 level (2-tailed)

Table 6 shows the descriptive statistics of the human intelligence network and employee loyalty with a mean response of 1.8261 and Std. deviation of 1.16043 for human intelligence network and a mean response of 1.8261 and Std. deviation of 1.26713 for employee loyalty and number of respondents (283). By careful observation of standard deviation values, there is not much difference in terms of the standard deviation scores. This implies that there is about the same variability of data points between the dependent and independent variables.

Table 7 is the Pearson correlation coefficient for human intelligence network and employee loyalty. The correlation coefficient shows 0.755 . The value indicates that correlation is significant at 0.05 level ( 2 tailed) and implies that there is a significant positive relationship between human intelligence network and employee loyalty $(\mathrm{r}=$ .705). The computed correlations coefficient is greater than the table value of $r=.195$ with 281 degrees of freedom $(\mathrm{df}=\mathrm{n}-2)$ at alpha level for a two-tailed test $(\mathrm{r}=.705, \mathrm{p}<.05)$. However, since the computed $\mathrm{r}=.905$, is greater than the table value of .195 we reject the null hypothesis and conclude that there is a significant relationship between human intelligence network and employee loyalty $(\mathrm{r}=.705, \mathrm{p}<.05)$.

\section{Findings}

Findings at the end of the research were:

1) Strategic intelligence significantly affects technological know-how in Innoson Limited $(r=0.602 ; F=3$, $426 \mathrm{E} 3 ; \mathrm{t}=4,426 ; \mathrm{p}<0.05)$

2) Innovation significantly affect brand reputation in the Innoson Limited $\left(X^{2}{ }_{C}=68.270\right.$ is greater than the ChiSquare table value $\mathrm{X}^{2}{ }_{1}=9,449, \mathrm{P}<0.05$ )

3) There is a significant relationship between human intelligence network and employee loyalty in Innoson Limited $(\mathrm{r}=, 705, \mathrm{P}<.05)$.

\section{Conclusion}

The study concluded that Competitive Intelligence is a vital tool for strategic planning and competitive advantage. In most organizations, Competitive intelligence is regarded as a system of environmental scanning that integrates the 
knowledge of all organizational members and encompasses marketing, structural, strategic and other organizational elements. Competitive intelligence (CI) is a continuous and evolving process by which businesses assess the behavior and capabilities of its current and potential competitors to assists in maintaining and developing a competitive advantage. It involves discovering, analyzing and using intelligence from publicly available, nonproprietary information sources and converting it into knowledge from the public basis. Competitive intelligence (CI) is a process for supporting both strategic and tactical decisions, and in order to support CI, organizations need systems and processes to gather and analyze reliable, relevant, and timely information that is available in vast amounts about competitors and markets. Competitive intelligence is more concerned with doing the right thing, than doing the thing right. The goal of a competitor analysis is to develop a profile of the nature of strategy changes each competitor might make, each competitor's possible response to the range of likely strategic moves other firms could make, and each competitor's likely reaction to industry changes and environmental shifts that might take place.

\section{Recommendation}

Based on the findings, the following recommendations were made.

1) There should be an adequate investment in competitive intelligence process, facilities, and activities by the manufacturing firm so as to be innovative, in their product, services and competitive dispositions.

2) In implementing competitive intelligence in an organization, employees should be equipped with the knowledge, skill and technical know-how of handling intelligence product,

3) Adequate resources should be made available for personnel to carry out effective competitive intelligence generation, sharing, distribution and deployment to areas of needs.

Management should ensure that intelligence generated from competitive intelligence activities are effectively deployed to areas of management priority so that the expected value addition of using such intelligence can be properly harnessed to the advantage of the firm.

\section{Acknowledgements}

The exploration of the author's thank other, from top to down/highest position to lowest position, contributor, participant, a supporter that was involved in completing the study. 


\section{References}

April, K., \& Bessa, J. (2006). A critique of the strategic competitive intelligence process within a global energy multinational. Problems and Perspectives in Management, 4(2), 86-99.

Barney, J. (1991). Firm resources and sustained competitive advantage. Journal of management, 17(1), 99-120.

Barney, J. B. (1986). Organizational culture: can it be a source of sustained competitive advantage?. Academy of management review, $11(3)$, 656-665.

Bergen, M, and Peteraf, M. A. (2002). Competitor Identification and Competitor Analysis: a Broad-based Managerial Approach. Managerial and Decision Economics, 23(4-5), 157-169.

Bergeron, M and Hiller, K (2002). Competitive Intelligence Professionals and their Interactions with CI Technology: A Research Agenda, Journal of Competitive Intelligence and Management, 3(1)43-56

Booker, Q.E., F.L. Kitchens And C.M. Rebman,( 2008). Examining the Use Of Competitive Intelligence in Staffing Municipal Police Department, An Exploratory Study. Issues in Information Systems, 3(1): 530-537.

Bose, R. (2008). Competitive Intelligence Process and Tools for Intelligence Analysis, Industrial Management and. Data System, 108(4), 510-528.

Britt, P. (2006). The New Competitive Intelligence: Raising the Confidence Quotient, KM World, November/December, 10-1 1 .

Bromwich, M. (1990). The Case for Strategic Management Accounting: the Role of Accounting Information for Strategy in Competitive Markets, Accounting, Organizations and Society,

Buhler, P. M. (2003) Managing in the New Millennium, Super Vision. 64( 8) 20

Calof, J. L. and Skinner, B. (1993\}, Competitive Intelligence for Government Officers: A Brave New World Optimum. 28(2) 38-42.

Coyne, J. And P. Bell, (2011). The Role of Strategic Intelligence in Anticipating Transnational Organized Crime: A Literary Review. Science Direct, 39(8): 60-78.

Cynthia A. B, Kofi F. Bl and Michael M.A (2014) Competitive Intelligence Information: A Key Business Success Factor, Journal of Management and Sustainability; 4 (2)

Day, G. S. and Wensley, R. (1988).Assessing Advantage: a Framework for Diagnosing Competitive Superiority. The Journal of Marketing, 52(2), 1-20.

Ezigbo. C.A and Uduji J.I. (2013) Manage Competitive Intelligence for Strategic Advantage. European Journal of Business and Management. 5(3)1-9.

Fatemeh, H And Habib, E (2014) Investigating the Relationship Between Technology Intelligence and Business Performance; Singaporean Journal of Business Economics and Management Studies 2(11) 1-9.

Gabber, H., (2007). Competitive Intelligence Topology Analyze for Improved Plan Operation. Industrial Management and Data Systems, 107(2): 198-236

Ifeanyichukwu, C. D., \& Peter, A. (2018). The Role of Sensory Marketing in Achieving Customer Patronage in Fast Food Restaurants in Awka. International Research Journal of Management, IT and Social Sciences (IRJMIS), 5(2), 155-163.

Kuosa. T.. (2011).Different Approaches of Pattern Management and Strategic Intelligence. Science Direct. 42(6): 458-467.

Mahmoud R, E (2014)A Study on the effect of the Strategic Intelligence on Decision Making and Strategic Planning, International Journal of Asian Social Science, 4(10): 1045-1061

Marlz. E. and Kholis A. K. (1996).Market Intelligence Dissemination across Functional Boundaries. Journal of Marketing Research. 33 (1)21

McGongale, J. J. and Vella, C. M. (2002) A Case for Competitive Intelligence: 90\% of the Information a Company needs to Understand its Market and Competitors and to make key Decisions is already Public. Information Management Journal. 36(4) 35-40

Meza, A. K. T., Aguayo, M. D. Z., Cevallos, M. G. O., \& Zambrano, P. F. R. (2018). Estimation of Resilience in University Students. International Research Journal of Management, IT and Social Sciences (IRJMIS), 5(1), 1624.

Nemutanzhela, P., and lyamu, T. (2011). The Impact of competitive intelligence on products and services innovation in organization. International Journal of Advanced Computer Science and Applications. 2(11)17

Ngugi, J. K., Gkure, R.V. and Mugo. H. (2012). Competitive Intelligence Practices and their Effect on Profitability of Firms in the Kenyan Banking Industry. International Journal of Business and Social Research (UBSR), 2(3), $11-18$

Nwokah, G, N. and Oodunka,F.. (2009) Competitive Intelligence and Marketing Effectiveness in Corporate Organizations in Nigeria, African Journal of Marketing Management. 1(1) 010-022 
Ogunsiji, A. S., \& Ladanu, W. K. (2017). A Theoretical Study of Performance Measures in the Strategic and Corporate Entrepreneurships of Firms. International Journal of Physical Sciences and Engineering (IJPSE), 1(1), 72-80.

Porter, M. E., (2008), The Five Competitive Forces that Shape Strategy. Harvard Business-Review, 3(9)86-104

Porter, M. E.. and V. E, Miller.(1985). How Information Gives You Competitive Advantage. Harvard Business Review 64(.4): 149-60

Ramsay, J. (2001), The Resource Based Perspective, Rents, and Purchasing Contribution to Sustainable Competitive Advantage. Journal of Supply Chain Management, 37(3), 38-47.

Raynor, M.E. (2007). The Strategy Paradox: why committing to Success Leads to Failure and what to do About it. New York: Currency Doubleday Press.

Rezaie.D. . Ghandehari, F and Amiri, F (2011) Analyzing the Impact of Competitive Intelligence on Innovation at Scientific Research Centers in Isfahan Science and Technology Town, Interdisciplinary Journal of Contemporary Research in Business, 3(5)7-13

Rizwan, R. A, Imamuddin, K. Khawaja A. A and Rana 1. P (2014) Competitive Intelligence and Marketing Effectiveness of Organizations: An Investigation From Pakistan, European Scientific Journal, 10(13) 1-12

Rumelt, D.P. (1984): Towards a Strategic Theory of the Firm, Alternative Theories of the Firm 2002-2: 286-300.

Saayman, N. and Mullen L.(2005). Competitive Intelligence: Construct Exploration, Validation and Equivalence, ASLIB Proceedings: New Information Perspectives, 60(4)383-411.

Schiele, Holger. (2012). Accessing Supplier Innovation by Being their Preferred Customer. Research-Technology Management, 55(1), 44-50

Singh, D. (2017). Leaf Phenology of Cassia Sieberiana L. in KSUSTA Campus of Kebbi State, Nigeria. International Journal of Life Sciences (IJLS), 1(1), 1-8.

Tej Adidam, P., Banerjee, M., \& Shukla, P. (2012). Competitive intelligence and firm's performance in emerging markets: an exploratory study in India. Journal of Business \& Industrial Marketing, 27(3), 242-254.

Viviers, W., Saayman, A, and Muller M (2005)," Enhancing a Competitive Intelligence Culture in South Africa," International Journal of Society Economics. 32 (7) 576-589.

Wheelen, E. and Hunger, A (2010) "Competitive Intelligence: Development and Practice", New York, Free Press 